Outros Tempos, vol. 19, n. 33, 2022, p. 90-116. ISSN: 1808-8031

DOI: http://dx.doi.org/10.18817/ot.v19i33.840

CHILE EN LA XII BIENAL DE PARIS, NOTAS SOBRE UN ENVÍO NO OFICIAL ${ }^{1}$

CHILE AT THE XII PARIS BIENNALE, NOTES ON AN UNOFFICIAL PARTICIPACION

CHILE NA XII BIENAL DE PARIS, NOTAS SOBRE UMA PARTICIPACION NÃO OFICIAL

\author{
CAMILA URRUTIA \\ ORCID: http://orcid.org/0000-0002-8441-191X \\ Doctoranda en Historia (PUC-Chile) \\ Santiago/Chile \\ camilaub@gmail.com
}

Resumen: Este artículo revisa la participación de Chile en la XII Bienal de París en 1982 como un caso de estudio para el ingreso al arte contemporáneo, entendido como período artístico. Desde esta aproximación, se analizan los textos que acompañan el envío chileno como parte de una construcción de escena, donde las narraciones que sostienen la lectura de la escena como tal, son parte integral de este envío, así como un síntoma de la contemporaneidad en las artes visuales chilenas. A partir de este análisis, el articulo tensiona la incorporación del arte chileno a en un orden global, en el contexto de la dictadura militar (1973-1989).

Palabras clave: Arte Chileno. Bienal de Paris. Arte Contemporáneo.

Abstract: This article reflects upon the Chilean participation at the XII Paris Biennale in 1982 as a case study for contemporary art insertion, understood as an artistic period. The texts that accompanied the exhibition are reviewed as part of a scene construction, where the narratives that hold together the reading of this scene as such are a crucial part of this show, as well as a symptom of contemporaneity in the Chilean visual arts. Through the analysis of these texts under the light of contemporary art as a period, the article presses the inclusion of the Chilean visual arts scene in a global order in the context of the military ruling that spanned from 1973 to 1989.

Keywords: Chilean Art. Paris Biennale. Contemporary Art.

Resumo: Este artigo revisa a participação do Chile na XII Bienal de Paris de 1982, como um estudo de caso para a inserção na arte contemporânea, entendida como um período artístico. Através dessa aproximação, analisam-se textos que acompanham o envio chileno como parte de uma construção de cena, onde as narrativas que sustentam a leitura da cena como tal, são parte integrante desse envio, assim mesmo, um sintoma de contemporaneidade das artes visuais chilenas. A partir desta análise, esse artigo tensiona a incorporação da arte chilena a um nível global, no contexto da ditadura militar entre os anos de 1973 a 1989.

Palavras-chave: Chile. Bienal de Paris. Arte Contemporânea.

${ }^{1}$ Artigo submetido à avaliação em agosto de 2021 e aprovado para publicação em dezembro de 2021. 
Outros Tempos, vol. 19, n. 33, 2022, p. 90-116. ISSN: 1808-8031

\section{Chile en la XII Bienal de Paris, notas sobre un envío no oficial}

La organización de una muestra de arte implica un trabajo de selección que puede ser comprendido, a su vez, como la edición del material que está disponible para ser expuesto y del que se decide mostrar una determinada parcela. A lo largo de este artículo, revisaremos la organización y el trabajo de edición promovido por la participación de Chile en la XII Bienal de Paris el año 1982, así como las impresiones que han quedado de este envío no oficial. Esta muestra encontró sus ejes de selección en distintos factores. Por una parte, el espacio "Bienal" sitúa a la muestra en un contexto internacional cuya organización expositiva está anclada, de una u otra manera, a la nacionalidad de las obras. Luego, París, ciudad anfitriona del evento, impone su presencia como un centro del arte occidental. A su vez, la cita en París exigía un límite de edad a los artistas que exhibían allí su obra, con el fin de sostener su perfil de exposición de arte joven $^{2}$.

Por otro lado, la invitación a participar de la XII versión en 1982 fue bajo una fórmula "no oficial", es decir, al margen de las relaciones diplomáticas entre la Bienal -en su carácter de encuentro entre países- y el Gobierno de Chile, suspendidas desde la interrupción de la democracia en 1973. Fue el contacto establecido entre Nelly Richard ${ }^{3}$ y Georges Boudaille curador de la Bienal-, lo que dio origen a un envío chileno autogestionado. En este sentido, la organización del envío chileno estuvo tensionado desde un comienzo por las direcciones que le imponía el espacio de exhibición, que podríamos resumir como: dar a conocer en un encuentro entre naciones, en uno de los centros del arte occidental, el arte joven realizado en el Chile dictatorial, desde una distancia explícita con la dictadura.

\footnotetext{
${ }^{2}$ La Bienal de París tiene su primera versión el año 1959. Inaugurada por Andrés Malraux, se propudo como una plataforma para los artistas emergentes, limitando la edad de los artistas exhibidos a un máximo de 35 años. En su primera versión, los organizadores sostienen: "A côté des prestigieuses expositions de Venise et de Saõ Paulo qui rendent hommage aux artistes ayant déjà pu affirmer leur personnalité et dont l'influence marque l'art de leur époque, nous avons choisi de faire de la Biennale de Paris un lieu de rencontre et d'expériences pour les jeunes, un lieu ouvert aux incertitudes et aux espoirs. Réservée aux artistes de moins de trente cinq ans, cette manifestation ne peut, comme les autres expositions, briller par l'éclat de ses vedettes". CATÁLOGO de la I Bienal de París. Disponible en: http://archives.biennaledeparis.org/fr/1959/ . Acceso en: 15 jun. 2017.

${ }^{3}$ Nelly Richard (1948) llegó a Chile desde Francia en 1970, y se incorporó a trabajar con Nemesio Antúnez en el Museo Nacional de Bellas Artes. Durante los años de dictadura la dictadura en Chile (1973-1989), formó parte activa de la escena de artes visuales en el país. Su texto Márgenes e instituciones: arte en Chile desde 1973, publicado en inglés por un medio australiano en 1986, forma parte de los textos fundamentales para comprender la organización de las artes visuales chilenas durante la dictadura.
} 
Outros Tempos, vol. 19, n. 33, 2022, p. 90-116. ISSN: 1808-8031

La coyuntura expositiva de esta Bienal ha sido revisada por la literatura reciente como parte de la circulación internacional de la Escena de Avanzada ${ }^{4}$-promovida y diagramada por Richard-, y su consolidación en ese espacio (VARAS, 2007); así como de un momento de desgaste de esta escena en el contexto local (MACHUCA, 2009; MACHIAVELLO, 2011). En ambas visiones, se señala la importancia que tuvo la inscripción de las obras en torno a una suerte de guion que permitió unir prácticas heterogéneas a conceptos comunes. De cierta manera, el desafío de dar a conocer el arte de vanguardia que se estaba haciendo en Chile en un contexto internacional, en donde los lenguajes utilizados por los artistas nacionales podían encontrar otras claves de entrada e interpretación, cristaliza los esfuerzos por inscribir y singularizar el envío chileno.

Por otra parte, en estos textos se relata la experiencia del envío desde una cierta decepción: el balance de Richard da cuenta de la dificultad que éste enfrenta para ser percibido en su novedad y no ser asimilado a formas artísticas anteriores ya inscritas en las historias del arte europeo y estadounidense. Más o menos plegados a esta reflexión, se abre en los comentarios una discusión respecto a una parte de la escena nacional que había tomado fuerza en el último año - y que había sido excluida de la exhibición en París- como un espejo de aquello que no dejó brillar a la muestra seleccionada. Se relata un "retorno a la pintura", que también acontecía a nivel local, como parte de las razones que eclipsaron el envío no oficial de Chile a este encuentro parisino. El desencuentro entre las expectativas y el resultado de la muestra, así como la voluntad de singularización de la escena por medio de la escritura, señalan para nosotros un momento que anuncia el proceso de un cambio para la producción y recepción de las artes visuales.

En las páginas que siguen revisaremos estos documentos - la inscripción que realizan y las impresiones que transmiten - para luego revisar la participación en la Bienal, sobre todo la sensación de no haber logrado transmitir la originalidad del envío, dentro de lo que hoy podemos percibir como el ingreso hacia el arte contemporáneo. Usamos esta etiqueta para identificar un periodo de producción de artes visuales, al que nos acercaremos a partir de tres textos: por una parte, Después del fin del arte. El arte contemporáneo y el linde de la historia, de Arthur C. Danto (2003); ¿Cuándo empieza el arte contemporáneo? / When does contemporary art begin?, de Andrea Giunta (2014); y The postconceptual condition or, the cultural logic of high capitalism

\footnotetext{
${ }^{4}$ Se conoce como "escena de avanzada" al grupo de artistas y obras de artes reseñadas por Nelly Richard en el texto Márgenes e Instituciones, así como en publicaciones anteriores. Las principales figuras reunidas en este concepto son: el grupo C.A.D.A, Eugenio Dittborn, Carlos Altamirano, Carlos Leppe, entre otros.
} 
Outros Tempos, vol. 19, n. 33, 2022, p. 90-116. ISSN: 1808-8031

today, de Perter Osborne (2014). A partir de la caracterización del arte contemporáneo desde las ideas de estos tres autores, revisamos las impresiones de este envío no oficial como un caso de estudio donde se logran vislumbrar las primeras señales de este nuevo período para el arte. Nos detenemos principalmente en la elaboración de una escena específica, a la luz de los textos que buscan colocar y singularizar esa propuesta. Ponemos especial atención a la búsqueda de legitimar el uso de los lenguajes artísticos que desarrollan, y su rendimiento para referirse a las condiciones de su emergencia en el contexto nacional. Sostenemos que narrar estas prácticas y articularlas como escena - "de avanzada" -, comienza a aparecer como una necesidad para distinguir unas obras de otras en un tiempo de intercambios y conexiones intensificadas, que caracterizan a lo contemporáneo del arte de un tiempo a esta parte.

\section{El envío chileno: la construcción de una escena no oficial.}

Se ha adelantado que la participación de Chile en la XII Bienal de París fue detonada por un encuentro. Nelly Richard coincide en las Jornadas de Crítica organizadas por el CAyC ${ }^{5}$ en Buenos Aires con Georges Boudaille, y desde allí se inicia el itinerario que la llevará a organizar el envío no oficial de Chile a la XII versión de este evento centrado en el arte joven. ¿Cómo responder a esta tarea que, entre otras cosas, significa abrir un espacio a la escena artística de un país que ha sido marginado de las últimas cuatro versiones de esta Bienal?

La elaboración del envío cargaba con una condición de "no oficial", a la que podemos ingresar desde distintas entradas. Por una parte, esta condición está adscrita a la naturaleza de la invitación de Boudaille a Richard. El encuentro que permite a las obras chilenas ir a la metrópoli francesa se enmarca en una suerte de diplomacia al margen de la institucionalidad, que deja a las obras chilenas fuera de la competencia oficial. En un estudio reciente, Julianne Debeusscher sostiene que la Bienal de París fue un espacio donde se dio este juego entre las representaciones oficiales y no oficiales. En este sentido, convivieron participaciones autogestionadas, como la chilena, con participaciones enmarcadas en las relaciones oficiales entre países ${ }^{6}$. La participación

\footnotetext{
${ }^{5}$ Inaugurado en 1968, el Centro de Arte y Comunicación (CAyC) fue una organización artística con base en Buenos Aires, centrado en el Arte de Sistemas. Jorge Glusberg fue uno de sus principales representantes.

${ }^{6}$ DEBEUSSCHER, Juliane. From cultural diplomacy to artistic and curatorial experimentation: the Paris Youth Biennale between 1965 and 1973. Institut of the Present, 2020. Disponible en:
} 
Outros Tempos, vol. 19, n. 33, 2022, p. 90-116. ISSN: 1808-8031

de Chile formó parte de esta interrelación, quedando del lado de los que exhibían al margen de la diplomacia institucional.

Sumado a esta primera imposición, el envío chileno se organizó desde el espacio no oficial en Chile, es decir, desde la oposición a la dictadura. Ahora bien, este espacio no era homogéneo, sino que incorporaba distintas respuestas a la situación política nacional. Si seguimos a Machuca y Berríos podemos distinguir, al margen del arte oficial, un arte comprometido, un arte contestatario o de protesta y, finalmente, un arte crítico (BERRIOS; MACHUCA, 2010, p. 69). En este esquema, podemos ubicar a Nelly Richard como una de las principales representantes del arte crítico, que luego será conocido como "Escena de Avanzada"7. La agrupación de distintas prácticas artísticas en torno a este concepto fue parte un proceso de distinción en el campo artístico no oficial de la dictadura. Al respecto, Richard ha sostenido:

No habría cómo entender el efecto irruptivo y disrruptivo del corte de la Escena de Avanzada que emerge en 1977, sin tener presente el fondo de contraste de estas otras prácticas artísticas del campo opositor con las que la Escena de Avanzada compartía una misma postura de rechazo antidictatorial pero de las que, al mismo tiempo, se separaba polémicamente debido a sus opciones de lenguaje radicalmente otras. (RICHARD, 2006, p. 69).

Esta coexistencia de aproximaciones hacia el arte en dictadura nos remite desde ya a un proceso de inscripción y distinción de las prácticas artísticas en el contexto local. En este sentido, la condición no oficial del envío chileno debió negociar con estas diferencias. Si bien es Richard quien recibe el encargo, la exhibición presenta una oportunidad única para el arte chileno de la época: organizar una muestra no oficial en cuanto tal, es decir, desde una articulación de conjunto. Más allá de la posibilidad de exhibir en el extranjero -no es ni la primera ni la única exhibición de artistas chilenos en el llamado primer mundo ${ }^{8}$ - lo excepcional es la posibilidad de organizar un guion expositivo para esa muestra, que sitúa al conjunto de estas prácticas frente a la

https://institutulprezentului.ro/en/2020/09/10/from-cultural-diplomacy-to-artistic-and-curatorial-experimentation-theparis-youth-biennale-between-1965-and-1973/. Acceso en: 19 mayo 2021.

${ }^{7}$ Los primeros textos que se refieren a las obras conceptuales chilenas de este período como "avanzada" aparecen en ediciones autogestionadas como el texto "Una mirada sobre el arte en Chile" de Nelly Richard. El concepto queda establecido luego con la edición de Márgenes e Instituciones en 1986.

${ }^{8}$ Como botón de muestra, se puede citar la intervención de Zurita en el cielo de Nueva York el mismo año de la Bienal. 
Outros Tempos, vol. 19, n. 33, 2022, p. 90-116. ISSN: 1808-8031

mirada internacional. Desde esta coyuntura expositiva se organiza el desafío de dar a conocer arte producido en "la periferia" y en dictadura. Richard recuerda:

[...] diría que lo "agitativo" a nivel local de nuestra participación en la Bienal de París ocurrió antes y no durante ni después del evento. Despertó una vital y polémica agitación de sentido preguntarse, entre nosotros mismos, por cómo la marginalidad resistente de una micro-escena chilena bajo dictadura debía hacerse presente en un escenario internacional como la Bienal de París [...] La aguda confrontación de puntos de vista entre nosotros mismos sobre estos problemas y dilemas fue mucho más importante que lo que ocurrió allá9.

La instancia de discusión respecto de cómo y quiénes iban a representar al arte no oficial chileno en dictadura es recordada también por artistas como Virginia Errázuriz y Raúl Zurita, quienes fueron parte del envío ${ }^{10}$. Errázuriz, quien participaba del Taller de Artes Visuales (T.A.V.) ${ }^{11}$ recuerda la organización de la Bienal como un momento de convergencia, en el que Richard recurre a los miembros del taller para organizar la selección de obras que viajarían a París. Asimismo, da cuenta de este evento en oposición a otras oportunidades en las que quienes comenzaban a ser denominados como avanzada excluían al T.A.V (GALENDE, 2007, p. 109). Por su parte, Zurita rememora el calor de la disputa respecto a la forma que ese envío debía tomar: "Hubo una vez una discusión a gritos, con furia. El Chile antidictadura había sido invitado a participar en una Bienal en París” (NEUSTDAT, 2001, p. 81). De acuerdo con la investigación de Luz María Williamson (2014), el Colectivo de Acciones de Arte (C.A.D.A), del que Zurita formaba parte, proponía un formato de telegramas que inundaran el espacio de Bienal con información del Chile dictatorial. Esta alternativa se vio confrontada por la apuesta de Richard y su propósito de dar a conocer las obras que se estaban perfilando como "escena de avanzada", en desmedro de la visión más política por parte del C.A.D.A (WILLIAMSON, 2014).

El encargo estaba en manos de Richard, y fue la escena escogida por ella la que viajó a Paris en representación del chile antidictadura, con la certeza de que no representaba necesariamente a todo el campo no oficial. A su regreso, el medio Pluma y Pincel realiza un

\footnotetext{
${ }^{9}$ RICHARD, Nelly. Nelly Richard sobre su curaduría para la Bienal de Venecia. [Entrevista cedida a] Lucy Quezada. Revista Artishock, 11 dic. 2014. Disponible en: http://artishockrevista.com/2014/12/11/nelly-richardcuraduria-la-bienal-venecia/. Acceso en: 10 jun. 2018.

${ }^{10} \mathrm{Su}$ participación está adscrita a las colectividades en las que colaboraban. Virginia Errázuriz en el T.A.V y Raúl Zurita en el C.A.D.A.

${ }^{11}$ Taller de grabado independiente fundado en 1974 por artistas exonerados de la Universidad de Chile.
} 
Outros Tempos, vol. 19, n. 33, 2022, p. 90-116. ISSN: 1808-8031

cuestionario a Richard, donde le pregunta por la poca representatividad del envío, a lo que ella responde:

Toda elección de obras o artistas (en cualquier circunstancia que se produzca y sea quien la establezca) es forzosamente parcial (puesto que siempre obedece a un criterio particular de elección) y como tal, excluyente; en lugar de querer enmascarar esa parcialidad o tendenciosidad inherente a cualquier operación de selección, me parece más honesto asumirla ${ }^{12}$.

Retomando, podemos pensar en el carácter no oficial de este envío desde dos ángulos complementarios: desde el origen de la invitación (que pone a Chile en el lugar de un invitado “especial"), y desde la imposibilidad de representar íntegramente la no oficialidad del arte chileno en dictadura. No oficial en la competencia internacional de la bienal, y no oficial como representantes de la antidictadura en Chile. El envío es, bajo este prisma, la aventura de la no oficialidad diagramada por Richard.

Las obras sobre las que trabajan los textos de Richard han sido categorizadas como parte del arte conceptual en Latinoamérica. Desde su momento de emergencia, estos conceptualismos reclamaron para sí una distancia con los precedentes europeos y norteamericanos ${ }^{13}$. El año 1979, Richard publicó en revista cal un texto titulado "El arte en Chile: una historia que se recita, otra que se construye", donde releva la importancia del momento histórico en el país como parte intrínseca del vuelco a un lenguaje conceptual del arte. Por otra parte, propone que ese lenguaje, en los antecedentes del norte del mundo, responden más bien a una evolución al interior de la práctica artística ${ }^{14}$. De cierta manera, el envío a la Bienal de París forma parte de esta voluntad de distinción que exige una legitimidad de origen propia para el arte conceptual chileno. Esta fue uno de los ejes de los textos que acompañaron a la muestra, y que revisaremos en detalle más adelante.

En el catálogo de la Bienal, la lista de los artistas seleccionados es la siguiente: Elías Adasme, Carlos Altamirano, el grupo C.A.D.A, Juan Castillo, Victor Hugo Codocedo, Eugenio Dittborn, Arturo Duclos, Diamela Eltit, Carlos Gallardo, Alfredo Jaar, Carlos Leppe, Gonzalo Mezza, Hernán Parada, Silvio Paredes, Ariel Rodríguez, Lotty Rosenfeld, Patricia Saavedra,

\footnotetext{
${ }^{12}$ Pluma y Pincel, n. 2, 11 enero 1983. p. 24.

${ }^{13}$ Para una discusión sobre conceptualismos latinoamericanos, revisar: Paulina Varas (2015).

${ }^{14}$ Cal, n. 2, jul. 1979.
} 
Outros Tempos, vol. 19, n. 33, 2022, p. 90-116. ISSN: 1808-8031

Marcela Serrano, Mario Soro, T.A.V (taller de artes visuales). Las obras seleccionadas consistieron en intervenciones que tenían al cuerpo, la ciudad o el paisaje como soporte. Para su exhibición, las distintas acciones fueron trasladas a sus registros fotográficos en un formato uniforme. Esto permitía la consideración de las obras en su conjunto y ponía de relieve las relaciones entre ellas - por ejemplo, la ciudad intervenida o la presencia del cuerpo en medio de los cuerpos ausentes-, a la vez que facilitaba su traslado. Además de las reproducciones fotográficas, Carlos Leppe llevó a cabo una performance en el baño de hombres. En la investigación de Carla Macchiavello (2011) se hace una descripción de esta acción, en la que Leppe se presentó en tenida formal, con una maleta, y leyó un texto en español que relataba un viaje en la cordillera de los Andes. Luego se desnudó y travistió de vedette, para bailar al son del Mambo Número 9 de Pérez Prado. A continuación, sentado en una silla comió y vomitó una torta mientras cantaba el himno nacional, para finalmente salir del baño y colapsar en el suelo, mientras sonaba en un tocadiscos "El día que me quieras" cantado por la madre del artista (MACCHIAVELLO, 2011, p. 92). Siguiendo la lectura de Macchiavello, esta acción de Leppe contenía elementos que podían potenciar una lectura europeizante de la única pieza "nueva" exhibida en la bienal. La asociación de lo latinoamericano con el exceso, el estereotipo de música "latina" que se reconoce en la música seleccionada, así como el encierro en lo intraducible del texto leído forman parte de los elementos que pueden volcar la lectura de la obra en un sentido distinto al esperado.

La elección del formato de reproducciones fotográficas de las acciones de arte mostró, por su parte, la dificultad de captar la singularidad de operaciones que alcanzan su máxima fuerza expresiva en el contexto donde emergieron. Una de las obras expuestas fue Para no morir de hambre en el arte, del grupo C.A.D.A, llevada a cabo en octubre de 1979. Esta acción se desarrolló con cuatro intervenciones simultáneas. Por una parte, los artistas del colectivo distribuyeron 100 litros de leche a 100 familias de un centro poblacional en la ciudad de Santiago. El mismo día, ocuparon una página de la revista "Hoy" y de un espacio del periódico "La Tercera de la Hora". A su vez, en la galería de arte Centro Imagen en Santiago de Chile, y en forma simultánea en Bogotá y en Toronto, se sellan cajas de acrílico con 60 bolsas de leche. Finalmente, se lee afuera de la sede la ONU en Chile, Bogotá y Toronto el texto "Esto no es una Aldea", en los cinco idiomas oficiales de las Naciones Unidas. Sobre estas cuatro acciones simultáneas, se siguen otras, como la intervención por parte de distintos artistas de las bolsas de 
Outros Tempos, vol. 19, n. 33, 2022, p. 90-116. ISSN: 1808-8031

leche vacías recolectadas en el centro poblacional. El C.A.D.A redactó un documento de 18 páginas en donde da a conocer los pasos de cada acción y los significados que ellos proponen (NEUSTADT, 2001, p. 107-125). Son múltiples las lecturas que se han realizado y las reflexiones que han surgido a partir de esta obra, como por ejemplo la alusión al programa de salud pública de la Unidad Popular "Medio litro de leche", que aseguraba el consumo de esta cantidad a los niños, embarazadas y nodrizas. Sin embargo, expuestas como registro en un escenario como la Bienal de París, en palabras de Richard, “[...] saturado de referentes internacionales" (RICHARD, 2020, p. 134), resulta complejo dar cuenta de las singularidades de esa acción de arte, activadas, sobre todo, por el momento histórico en que se realizaron.

En un texto reciente de Richard sobre la Bienal (RICHARD, 2020), aparecen dos fotografías de las exhibiciones. En ellas se puede advertir la presencia de una obra de la serie $A$ la carne de Chile, de Carlos Gallardo, así como una imagen de la serie Estudios de la felicidad de Alfredo Jaar. Ambas series habían participado en Chile en el Concurso de la Colocadora Nacional de Valores en el Museo Nacional de Bellas Artes. De hecho, Gallardo se encontraba en Paris el año 1982 gracias a una beca recibida como premio en la edición de 1979 de ese certamen. Por su parte Jaar fue premiado con la misma beca el año 1981, con la cual partió a Nueva York. La reproducción de las obras de estos dos artistas pone de relieve, en el espacio de la Bienal, el aspecto no binario de la relación de las artes visuales con la institucionalidad intervenida en Chile. Esta consideración nos devuelve al asunto de las demarcaciones del espacio no oficial. La marginalidad de las prácticas conceptuales se tensiona con estas infiltraciones en los lugares del oficialismo. Al respecto, Richard sostiene en Márgenes e instituciones que la avanzada ocupó los espacios que se ofrecían y funcionó de una manera contra institucional. A su vez, se refiere al peligro que esas obras corren al estar expuestas a la crítica oficialista, la que, a ojos de Richard "[...] neutraliza el coeficiente crítico de las obras que recoge" (RICHARD, 2009, p. 124-126). El principal factor de neutralización de las obras es dirigirlas a modelos internacionales, sin rescatar la singularidad del medio en el contexto histórico en el que emerge. En este sentido, la avanzada puede circular sus obras por los espacios oficiales porque los espectadores desatienden la verdadera singularidad de sus prácticas, y con ello el potencial político de estas.

El problema de la neutralización forma parte de las expectativas del envío a Paris. Como hemos advertido, si revisamos los textos que acompañaron a las obras en la capital francesa, vemos que el mantra que se repite es la caracterización de las dificultades que encuentra 
Outros Tempos, vol. 19, n. 33, 2022, p. 90-116. ISSN: 1808-8031

el envío chileno para ser percibido en su singularidad. Por una parte, en el catálogo Richard reseña la participación de Chile con un texto titulado "Une situación...", compuesto por siete párrafos que comienzan con la pregunta "Comment donner a lire" (BIENNALE DE PARIS, 1982, p. 67), en el que la autora insiste en las dificultades que enfrenta la singularización de la escena chilena en el contexto internacional. ¿Con qué claves de lectura se puede dar a conocer el arte de una periferia marginada por su situación política, sin plegar sus manifestaciones a la historia del arte de los centros?

Por otra parte, la revista Art Press dio un espacio especial de su número 62 - dedicado por completo a la bienal - al envío chileno. Allí se incluyeron textos de Richard, Eugenio Dittborn, y el grupo C.A.D.A titulados: "Le Chili comme scène de revendication", "Nous les artistes des provinces lointaines" y "L'avant garde chilienne"; en el espacio también se anunció una acción de arte de Carlos Leppe. Con distintas aproximaciones y tonos, los tres textos hacen alusión al carácter "original” de las obras de arte que presenta Chile en la Bienal. En este sentido, buscan exponer las imposiciones del centro sobre la periferia a la hora de leer las manifestaciones artísticas de los "países lejanos". Hay una intención de sustraer el envío chileno del orden de la historia artística de los centros. Desde esta consideración, se declara la no pertenencia de las prácticas chilenas a esa cadena de sucesiones, sino que se les da el peso de una novedad y singularidad atadas a las circunstancias en que esas manifestaciones han surgido y a la operatividad que han cumplido en sus momentos de emergencia. El texto de Richard hace alusión al peligro de la sanción del déjà vu:

Ainsi, la notion de "déjà $v u$ " qui sanctionne habituellement l'appréciation des
formes susceptibles d'être facilement renvoyées aux modèles européens ou
americains, répond implicitement à la norme totalitaire d'une histoire qui
obligerait toute pratique née d'une ailleurs à se plier à son propre ordre
d'apparitions en tant qu'ordre prioritaire ${ }^{15}$.

Casi como profecía autocumplida, la sensación que predominó luego del envío, y que subsiste en los textos que lo recogen, es efectivamente la de una escena que no logra comunicar su originalidad. En Chile, Richard reseña la experiencia de la bienal en La Separata con párrafos muy similares a los que aparecieron en el medio francés:

\footnotetext{
${ }^{15}$ Art Press, n. 62, sept. 1982. p. 15.
} 
Outros Tempos, vol. 19, n. 33, 2022, p. 90-116. ISSN: 1808-8031

La sanción colonialista del "déja $v u$ " frustra así el [al] espectador de la posibilidad de validar trabajos que -si bien fueron elaborados a partir de repertorios culturales de figuras ya existentes y extranjeras- son capaces de reactivar esas figuras (de reprocesar sus órdenes de interrelacionamientos [sic] socioculturales) ejerciendo sobre ellas una torsión crítica que las hace significar diferentemente ${ }^{16}$.

En este sentido, la no oficialidad del envío chileno, su condición de "margen” tanto al interior de la bienal, así como de representante del chile antidictadura, se proyectó también a una recepción fuera de los parámetros de la escena que se quería presentar. Un envío no oficial que generó una lectura fuera del guion "oficial” escrito por Richard.

Esta sensación tuvo a su vez una lectura en el campo artístico chileno respecto al desgaste de las prácticas conceptuales, las que palidecían frente a un colérico "retorno a la pintura" que se vivía en la escena local. La participación en la bienal potenció una lectura de contrastes entre arte conceptual y retorno a la pintura, pues parte de la incomprensión del envío chileno se juzgó a partir de las modas transvanguardistas y neoexpresionistas exhibidas en la cita internacional. La sensación del dejà $v u$ se veía reflejada en las nuevas tendencias, que dejaban atrás el arte conceptual de los años sesenta y setenta. Así, Richard sostiene en Pluma y Pincel en 1983:

Me pareció, entre otras cosas, que la emergencia de esas formas chilenas (esas formas de "intervención del cuerpo social como soporte de creatividad") dentro de un contexto marcado por el éxito del modelo transvanguardista (de un modelo que promueve el reposicionamiento de la pintura en contra de las utopías de la vanguardia) volvía aún más patente lo que nos separa de esas culturas (europeas o norteamericanas) ${ }^{17}$.

La distancia de la escena chilena presentada en la bienal se distinguía de los referentes externos para el arte conceptual, pero también del retorno a la pintura. El investigador Guillermo Machuca sostuvo que el contexto de la bienal fue leído como un espacio donde brillaban las estéticas neoexpresionistas y transvanguardistas y que era "[...] en este contexto donde había que presentar una vanguardia local antagónica respecto de la vuelta transvanguardista de la pintura" (MACHUCA, 2009, p. 78).

\footnotetext{
${ }^{16}$ La Separata, n.6, out.1983. p. 1.

${ }^{17}$ Pluma y Pincel, n. 2, 11 enero 1983. p. 24.
} 
Outros Tempos, vol. 19, n. 33, 2022, p. 90-116. ISSN: 1808-8031

Ahora bien, este juicio, en donde las prácticas de la "escena de avanzada" se perciben como anticuadas gracias al revuelo del regreso a la pintura impulsado por la Transvanguardia italiana, puede ser comprendido como una impresión local que traduce la problemática nacional al escenario del encuentro internacional. En el número que ya hemos citado de Art Press, la editorial de la revista da cuenta de los bemoles del retorno a la pintura en el escenario de intercambios globales que supone un encuentro como la Bienal de Paris. En su editorial propone una crisis de las artes plásticas frente al auge de nuevos medios para el arte, principalmente el sonido y el video -que tienen sus propias secciones al interior de las páginas de la revista, no así la pintura-, dejando abierta la pregunta respecto al supuesto éxito del modelo transvanguardista: "Le grand question que se pose le spectateur en pénétrant dans cette section Arts Plastiques c'est: ¿les années 80 seront-elles oui o non celles de retour à la peinture?"18. Si consideramos la percepción de esta editorial, el éxito del retorno a la pintura no estaba asegurado en el escenario internacional.

Si volvemos a la escena nacional, nos encontramos con una escena que ya estaba mostrando señales de fatiga, incluso antes de la bienal. De acuerdo con las investigaciones de Carla Macchiavello (2011) y de Luz María Williamson (2014), la exposición “Con Textos”, realizada en la Galería Sur de Santiago en abril de 1982, fue una suerte de ensayo de lo que sería luego la muestra en París. Esta exposición es reseñada en La Separata con opiniones encontradas. Nelly Richard propone desde el título de su reflexión una mirada disconforme, señalando a la muestra como "un marco de desalentamiento". Busca explorar las relaciones entre el grupo de obras que se han reunido y cómo se relacionan entre ellas, para luego pensar la muestra en términos de las obras que se presentan. El ejercicio le deja la sensación de una exhibición a la que le falta el dinamismo crítico que las obras tuvieron en otras presentaciones. Por su parte, Francisco Brugnoli titula su reflexión "Una fatiga, un agotamiento", donde llama la atención sobre una "[...] marginalidad, cada vez más aguda"19, presente en la muestra.

Por su parte, Justo Pastor Mellado ${ }^{20}$ en un seminario organizado por el T.A.V. en 1983, considera que en abril de 1982 -fecha de la exposición Con Textos- las obras todavía tenían su fuerza crítica, pero que esta comienza a decaer luego de la bienal, para dar cuenta del guion

\footnotetext{
${ }^{18}$ Art Press, n. 62, sept. 1982. p. 6-8.

${ }^{19}$ La Separata, n. 2, mayo. 1982. p. 2.

${ }^{20}$ Justo Pastor Mellado (1949), es un crítico de arte chileno que comenzó a escribir sobre arte a fines de los años 70. La mayor parte de sus textos de esa época se encuentra en catálogos, o publicaciones independientes como la de este seminario.
} 
Outros Tempos, vol. 19, n. 33, 2022, p. 90-116. ISSN: 1808-8031

que las sostenía. Mellado se refiere en esa ocasión a la fuerza que tiene la inscripción de las prácticas artísticas en torno a un concepto. Si bien se refiere a un momento de desgaste de la escena reunida por Richard, llama la atención el uso del concepto "ficción literaria". Con este, da cuenta de la importancia del discurso en la articulación de un grupo que, en realidad, no lo es más que desde la teorización de unas prácticas más bien diversas. Mellado señala: “[...] la situación provocada por la convocación a la Bienal sólo cierra un período para marcar el inicio de otro. Su desconstitución no significa desandar un camino, sino la disolución de la ficción que la sostenía a nivel del discurso [...] la escena se diluye como posibilidad colectiva" (MELLADO; RICHARD, 1983, p.19). En este sentido, el comienzo del desgaste tenía que ver con el guion que unía a estas obras para proponerlas como escena.

En sintonía con la lectura de Mellado, Guillermo Machuca sitúa al año 1982, con la Bienal de París como hito, como el comienzo de "[...] la deflación del arte de avanzada a manos de una generación de pintores de recambio, la mayoría inspirados en las corrientes pictóricas internacionales en boga en dicho momento" (MACHUCA, 2009, p. 80). El regreso a la tela es concebido por esta generación más joven como una oposición a las demarcaciones teóricas que imponía el arte de la avanzada. Una de las figuras de esta nueva aproximación es Samy Benmayor, quien, en el catálogo de la exhibición de 1986 Cabeza Partida, resume su postura con las siguientes palabras: "El año 1981 estuve en Nueva York. Viví un año por allá. Cuando volví, traté de descifrar la aproximación al arte de 'intelectuales' y descubrí que me era ajena. Me aboqué entonces a lo que me importaba" ${ }^{21}$.

Por otra parte, la escena chilena a principios de la década de 1980 está, en cierta medida, marcada por la crisis económica que comienza a fines de 1981. Entre 1975 y 1981, hubo una suerte de alianza entre la empresa privada y el arte, que llenó parte del vacío que había dejado la intervención estatal y el cambio de modelo de desarrollo hacia un estado subsidiario. Esta alianza permitió la existencia de concursos como el que ganaron Jaar y Gallardo. De acuerdo con la visión de Galaz e Ivelic, el retorno a la pintura está enmarcado en Chile por el colapso económico y la desaparición de esas instancias, las que de alguna manera promovieron un arte "no comercial". Por el contrario, la generación joven se vio en la urgencia de generar un arte que pudiese entrar al mercado (GALAZ; IVELIC, 1988, p. 331-332). Sumado a esta situación, el

\footnotetext{
${ }^{21}$ Catálogo de la exposición Cabeza Partida. CENTRO DE DOCUMENTACIÓN DE LAS ARTES VISUALES. Cabeza partida. Galería Plástica 3, Santiago de Chile, ago. 1986. Disponible en: http://centrodedocumentaciondelasartes.cl/g2/collect/cedoc/images/pdfs/4041.pdf. Acceso en: 19 mayo 2021.
} 
Outros Tempos, vol. 19, n. 33, 2022, p. 90-116. ISSN: 1808-8031

impulso de la pintura también se atribuye, para el caso chileno, al retorno en 1982 de algunos artistas exiliados, donde destacan Gracias Barrios y José Balmes, representantes de la continuidad de la pintura.

En este contexto se enmarca la disputa de la legitimidad del llamado "retorno a la pintura" en Chile, que es leído desde la vanguardia como una alineación con las pautas que dictan las metrópolis. Una repetición acrítica de las modas que predominan en el mercado internacional. Un botón de muestra de esta actitud se puede encontrar en el número 5 de la publicación La Separata, donde conversan entre sí las apreciaciones de la muestra "Zapateo Americano", en la que exhiben Samy Benmayor y Jorge Tacla, con un extracto del texto de Joseph Kosuth Necrophilia Mon Amour y algunas apreciaciones críticas de Nelly Richard sobre "La Transvanguardia italiana" de Achille Benito Oliva. Como bien indica Macchiavello (2011), esta publicación se dirige en contra de la pintura en Chile a partir de autores extranjeros. En este sentido, la escena de escritura y de vanguardia que se quiere distanciar de los referentes internacionales, incorpora la discusión local a una discusión más amplia por medio de las relaciones que se establecen a partir de esos textos con la escena chilena. Esta operación pone de manifiesto la atención en Chile respecto a la información que circulaba en el exterior sobre el arte del momento. Chile efectivamente es un país lejano, que se encontraba desconectado por la vía política de muchos eventos internacionales como la Bienal, es una periferia de los centros occidentales, pero, aun así, estaba insertado, de forma precaria y con bemoles que podemos seguir advirtiendo, en el circuito internacional de las artes. La información, de una u otra manera, circuló $^{22}$, y la discusión en torno al retorno a la pintura era una discusión legítima al interior de la escena chilena.

En este sentido, la evaluación de Richard acerca de aquello que distancia a Chile del retorno a la pintura, es también una distancia con lo que se está gestando a nivel local y que puede parecer una repetición o una recitación, opuesta a lo que ella propone: la construcción de una escena. Desde esta perspectiva, la participación de Chile en el evento internacional lleva inscrita la elaboración de esa escena, con la que debe contrastarse no sólo ante el otro externo, sino que también frente a los demás actores a nivel nacional. La sensación general en el medio local, y la lectura posterior que se ha hecho, dan cuenta de una suerte de quiebre de esta escena que estaba siendo construida. Sin embargo, el comienzo de la circulación internacional de los

${ }^{22}$ Una de las formas principales de circulación, además de los viajes que muy pocos podían hacer, fue por medio de revistas de arte. 
Outros Tempos, vol. 19, n. 33, 2022, p. 90-116. ISSN: 1808-8031

actores de la escena de avanzada da pie a la articulación más concreta, desde una perspectiva teórica, de lo que fueron esas prácticas. El sello de la avanzada queda inscrito con la publicación de Márgenes e instituciones, en inglés en un medio extranjero en 1986. Tal vez podemos considerar que con este hito culmina el ciclo de la escena de avanzada por medio de la inscripción de sus prácticas desde una elaboración teórica que insiste en la distancia de estas obras, que usan lenguajes importados, con el antecedente internacional de esos lenguajes, singularizándolo para su circulación en el extranjero. Enfrentada al flujo de los lenguajes artísticos que circulan desde una parte del mundo a otra, Richard deberá insistir en la distinción de las prácticas chilenas para sostener un discurso inaugural del arte de avanzada respecto a las otras prácticas del medio local, las que, a su vez, también se nutren de esos lenguajes móviles.

\section{Ingreso al Arte Contemporáneo}

En este punto, introducimos una breve caracterización de lo que denominaremos el ingreso a un período de arte contemporáneo. Nos referimos al arte contemporáneo como categoría de periodización revisando a ésta como la organización de horizontes perceptivos comunes que permiten revisar determinados corpus de obras de acuerdo a razones de ser del arte, no sólo en términos de un estilo -por ejemplo Barroco -, sino más bien desde las ideas que animan la producción artística. En este sentido, las categorías de periodización contienen un componente histórico importante: el tránsito de un período artístico a otro puede dar cuenta de las variaciones -cambios y continuidades- respecto a lo que se espera y es concebido como arte. O, en términos de Howard Becker, de las mutaciones que se pueden advertir en las convenciones de un determinado mundo artístico (BECKER, 2008). La propuesta que sigue, para el arte contemporáneo como categoría de periodización, está tomada de los análisis realizados por: Arthur C. Danto en Después del fin del arte. El arte contemporáneo y el linde de la historia (2003); Andrea Giunta en ¿Cuándo comienza el arte contemporáneo / When does contemporary art begin? (2014); y Peter Osborne en "The postconceptual condition, or the cultural logic of high capitalism today" (2014).

La pregunta por el arte contemporáneo como período artístico responde, en los textos explicitados más arriba, a la percepción de un agotamiento de las etiquetas "moderno" y 
Outros Tempos, vol. 19, n. 33, 2022, p. 90-116. ISSN: 1808-8031

"posmoderno" para dar cuenta de la producción artística que se viene haciendo de un tiempo a esta parte en distintos lugares del mundo. En estos análisis ese agotamiento está relacionado con cambios en las estructuras sociales que repercuten en la forma de aproximarse al sentido del arte y a la producción de este. Para el período que estamos revisando, este cambio está dado por un giro hacia la globalización, comprendida como: “[...] the effect of the relative global deregulation of capital markets, or, more specifically, the relative denationalization of the regulation of markets in finance capital" (OSBORNE, 2014, p. 21). Son cambios que conciernen a las formas de producción, conexión y circulación de bienes, y que tienen influencia en la noción de tiempo y espacio para los individuos sujetos a esos cambios, que, a su vez, tienen efectos para la composición de un tiempo contemporáneo sobre el moderno.

Para este breve análisis, describiremos al arte moderno - y la temporalidad que lo sostiene -, desde un orden progresivo y un tiempo proyectivo. En palabras de Giunta: "Desde el paradigma de la modernidad, se entiende que el arte progresa. A cada transformación del lenguaje le sucede otra, que resuelve problemas que dejó pendiente la anterior" (GIUNTA, 2014, p. 9). Danto, por su parte, comprende esta progresión en términos de un relato de la historia del arte, donde se van incorporando las distintas manifestaciones al orden establecido por el desarrollo de ésta, cuyo último gran relato sería el de Clement Greenberg. El paso al tiempo contemporáneo se advierte, para estos dos autores, cuando se derrumba el orden que indicaba la progresión y “[...] el arte deja de evolucionar” (GIUNTA, 2014, p.10), lo que, en términos formales, comienza a advertirse cuando "el mundo real irrumpe en el mundo de la obra". Esta aseveración tiene su eco en el diagnóstico de Danto enfrentando a la exposición de Andy Warhool de las Brillo Box, frente a la que cuestiona: “¿cuál es la diferencia entre una obra de arte y algo que no es una obra de arte cuando no hay entre ellas una diferencia perceptiva interesante?" (DANTO, 2003, p. 28). Para el sentido que hemos indicado, esta percepción refuerza la idea de que no hay un guion que sostenga el desarrollo del arte cuando este ha entrado en su etapa contemporánea. No hay un relato oficial.

Siguiendo esta línea, proponemos que una de las características del arte contemporáneo es el fin de un sentido progresivo o evolutivo al interior de la práctica artística. En el título del texto de Danto esta idea se condensa en la imagen del "linde de la historia": lo que está más allá del relato del arte moderno. Salir de la historia se traduce para el arte contemporáneo en una des-programación de los ritmos y pautas, permitiendo, a su vez, una 
Outros Tempos, vol. 19, n. 33, 2022, p. 90-116. ISSN: 1808-8031

descentralización -al menos conceptualmente- para el desarrollo del arte, dando cabida a aproximaciones novedosas para responder a este cambio en distintas partes del mundo. Giunta se refiere a este proceso como el de "vanguardias simultáneas" que van desdibujando el esquema de los centros y periferias para leer el desarrollo del arte. En términos formales esto significa que, de un tiempo a esta parte, se ha hecho una borradura sobre la línea que trazaba un desarrollo progresivo de un estilo a otro para poner en un plano todas las formas artísticas heredadas como materiales disponibles para su uso y re-significación. Danto lo pone en los siguientes términos: “[...] lo contemporáneo es, desde cierta perspectiva, un período de información desordenada, una condición de perfecta entropía estética, equiparable a un período de casi perfecta libertad" (DANTO, 2003, p. 34); en el que: “[...] los artistas se liberaron de la carga de la historia y fueron libres para hacer arte en cualquier sentido que desearan, o sin ninguno. Esa es la marca del arte contemporáneo" (DANTO, 2003, p. 34).

Peter Osborne, por su parte, sostiene que el arte contemporáneo, críticamente comprendido, es un arte postconceptual, en tanto heredero de la experiencia histórica compleja y el legado crítico del arte conceptual, cuyas prácticas experimentales desarrollaron mutaciones fundamentales para la obra de arte (OSBORNE, 2014, p. 25). En cierto sentido, hay una conexión entre la idea de liberarse de un arte que progresa, con la manera en que Osborne comprende la herencia del arte conceptual: a partir de éste, se expanden hacia el infinito los medios materiales del arte (OSBORNE, 2014, p. 26). Es decir, virtualmente cualquier cosa puede ser o formar parte de una obra de arte. La etiqueta postconceptual es comprendida como una condición en un sentido doble: de una parte, como la condición del arte contemporáneo en términos de una situación artística; y, de otra, desde las condicionantes externas que se imponen al desarrollo del arte - "[...] primarly, that interplay of communications technologies and new forms of spatial relations that constitute the cultural and political medium of economic processes of globalization" (OSBORNE, 2014, p. 25).

Desde el título de su artículo - The postconceptual condition, or de cultural logic of high capitalism today (en paráfrasis de los textos La condición posmoderna. un informe sobre el saber y Posmodernismo, o la lógica cultural del capitalismo avanzado) -, Osborne busca conectar las formas artísticas del presente con las lógicas de desarrollo del mundo, las mutaciones en términos de espacio y tiempo, para proponer una aproximación donde la obra de arte en tanto categoría es capaz de iluminar respecto a estos procesos, refiriéndose al arte en términos de 
Outros Tempos, vol. 19, n. 33, 2022, p. 90-116. ISSN: 1808-8031

conocimiento. En este sentido, dar cuenta de aquello que condiciona al arte contemporáneo - en el caso de Osborne su "postconceptualidad"-, puede ayudar a comprender el mundo en el que este surge.

Osborne propone que el concepto de arte contemporáneo como período se formaliza a fines de la década de los noventa, junto con el declive de las fórmulas posmodernistas (OSBORNE, 2014, p. 19-20). Sin embargo, los cambios estructurales que van diagramando el viraje a una contemporaneidad para las artes visuales, son anteriores. Para Giunta uno de los hitos de este desvío es la Segunda Guerra Mundial, con la cual se inicia un desplazamiento de Paris como centro del itinerario para la formación artística. Si bien este es un hito global, la misma autora indica que para América Latina uno de los hitos que promueve el desarrollo de un arte contemporáneo son los gobiernos militares que tuvieron lugar en la región entre las décadas de 1960-80. En esta aproximación, distintos eventos de la historia reciente van influyendo en una determinada manera de aproximarse a la producción artística. Esta forma, que hoy llamamos “arte contemporáneo", tiene sus antecedentes en nuestra historia reciente: proponemos que el momento expositivo que estamos revisando se enmarca en esta etapa de antecedente, dando cuenta de unas primeras señales de esta vertiente contemporánea.

\section{Estudio de caso}

Retomamos ahora el análisis sobre la participación de Chile en la XII Bienal de Paris, para revisarlo a partir de las características que hemos expuesto para el arte contemporáneo. Hemos delineado en la caracterización del envío como "no oficial" las aristas de esta participación. De un lado, está el desafío de organizar una muestra explícitamente al margen de la dictadura. Como hemos visto, esta tarea da cuenta de las distintas posturas al interior del campo opositor, así como de las operaciones de demarcación que debe realizar la escena que se exhibe en París para diferenciarse. Por otra parte, las construcciones conceptuales que organizan la unidad expositiva del envío se enfrentan a las imposiciones de la historia del arte de los centros. Por último, advertimos la competencia por distintas formas legítimas de arte (escena de avanzada versus retorno a la pintura). 
Outros Tempos, vol. 19, n. 33, 2022, p. 90-116. ISSN: 1808-8031

Retomamos la visión de Machiavello, que recoge este hito desde la perspectiva de la construcción de la Escena de Avanzada, deteniéndose en las formas de demarcación a partir de las cuales ésta se fue configurando. La exposición de esta escena en París, y, sobre todo, la decepción que relatan los participantes, son reseñados como consecuencia de una vanguardia que intentó definirse en términos autorreferentes: sin reconocer modelos ni herencias, la posición insular que toma le impide salir del aislamiento al que se auto confina (MACHIAVELLO, 2011, p. 110). Tomamos esta reflexión como punto de inicio, pues da cuenta de dos asuntos que a nuestro juicio son claves en el ingreso a un arte contemporáneo. En primer lugar, la elaboración de la escena: agrupar en un horizonte conceptual, en una narración o ficción literaria -como le llama Justo Pastor Mellado (MELLADO; RICHARD, 1983, p. 25-26) - distintas prácticas con el fin de darlas a conocer bajo los parámetros de esa narración. En segundo lugar, el problema de la herencia de las formas artísticas ya elaboradas e inscritas en la historia del arte europeo y norteamericano.

Comencemos por este último punto. Una de las características que hemos descrito para el arte contemporáneo es la disponibilidad de los lenguajes artísticos, no para superar lo que éstos no resolvían, sino que como insumos para la creación de nuevas obras. Se desprenden de la línea evolutiva que sostenía una proyección, para quedar en un plano y ser reelaborados con el sentido que quieran darle los artistas. Otra de las características que revisamos, y que puede desprenderse de la anterior, es la descentralización de las pautas artísticas que da paso a lo que Andrea Giunta denomina "vanguardias simultáneas". El momento expositivo que revisamos es sintomático de estas dos características en el siguiente sentido: coloca en uno de los "centros" del arte occidental -París-, obras herederas de los lenguajes de las denominadas vanguardias históricas, reclamando para éstas -en los textos que dan cuenta de la muestra- una legítima novedad para las obras expuestas, determinada por su origen. La sanción de dejà vú contra la que lucha la escritura de Richard, es señal del reclamo por la simultaneidad de las vanguardias: en las periferias del arte occidental, surgen respuestas específicas que resignifican desde sus singularidades la tradición heredada y la devuelven a los centros, removiendo y desplazando los relatos centralizados de la historia del arte, así como la lectura evolutiva de los lenguajes artísticos.

Por otra parte, la idea de que en el campo artístico nacional la discusión entre los actores estuviese centrada en un "retorno a la pintura", de manera similar a lo que ocurría al 
Outros Tempos, vol. 19, n. 33, 2022, p. 90-116. ISSN: 1808-8031

interior de la Bienal, puede plantearse como una forma esquemática de repetir en la periferia lo que viene desde el centro -la lectura que hace Richard de la situación-, o bien puede revisarse como una discusión que trasluce un grado de inserción de la escena nacional con una escena más bien global, donde la legitimidad de la apropiación de los lenguajes -ya sean los experimentales de las vanguardias por parte de la escena de avanzada, o una vuelta a la pintura-, no está señalada más que por las lecturas que se hagan de ellas.

En este sentido, para singularizar las prácticas y proponer la novedad de éstas, la escritura sobre arte toma un papel fundamental: permite promover una determinada lectura sobre un cuerpo de obras y ponerlo en circulación desde un eje perceptivo. Retomamos el razonamiento de Danto y su idea de que el modernismo sería el último gran relato del arte moderno, tras el cual traspasamos la historia en términos de una narrativa que propone un orden progresivo para la evolución de los lenguajes artísticos. Cuando damos importancia a la escritura sobre arte no reestablecemos el ánimo de una historia del arte en el sentido que acabamos de describir, sino más bien damos cuenta de un compañero de ruta que no lo abandona en su tránsito desde lo moderno a lo contemporáneo, sino que más bien continúa acentuando su importancia, sobre todo entendiendo que nos encontramos en un momento en que lo artistas pueden hacer arte parafraseando a Danto - con el sentido que quieran o sin ninguno. Dada esta marca, la disponibilidad de las prácticas artísticas para su interpretación promueve lecturas críticas sobre éstas que vayan organizando horizontes perceptivos para los espectadores. Esta situación se hace cada vez más visible en las exposiciones de arte contemporáneo, donde la figura del curador crece en importancia, tomando a las obras como insumos para proponer distintas ideas desde el $\operatorname{arte}^{23}$. En consecuencia, los catálogos de las exposiciones y las revistas especializadas se vuelven cada vez más relevantes para dar cuenta de las múltiples formas que toma el arte, a través de distintas miradas. Pensamos que para el caso que hemos revisado, los registros dan cuenta en dos sentidos de este papel de la escritura. De una parte, en la creación de una escena: los escritos de Richard son los que promueven una unidad perceptiva para obras heterogéneas, que son propuestas desde una narración determinada. Por otro lado, el registro de las tensiones asociadas a la muestra en Paris promueve una reflexión -a posteriori- sobre las inscripciones que realiza la escritura sobre arte.

\footnotetext{
${ }^{23}$ Ver: O’Neill (2007).
} 
Outros Tempos, vol. 19, n. 33, 2022, p. 90-116. ISSN: 1808-8031

Si bien la escritura sobre arte no está presente como temática para los textos con los que hemos descrito al arte contemporáneo, pensamos que nuestro caso de estudio pone de manifiesto la importancia de ésta para comprender la apertura que supone el ingreso a este nuevo período artístico. La herencia del arte conceptual, tal como la describe Osborne, expande los límites de la obra de arte hacia el infinito. Danto da cuenta de esta expansión en la libertad de sentido con la que trabajan los artistas, y en términos formales, con la disponibilidad de la historia del arte como insumo para la elaboración de nuevas obras de arte. La exposición organizada por Richard exhibe estas dos herencias, pero esas obras adquieren espesor y significado en el flujo de los intercambios por medio de inscripciones en una narración que distingue una pequeña parcela de la producción artística nacional, desde la que circulan las ideas sobre estas prácticas.

\section{Reflexiones finales}

A lo largo de este artículo hemos propuesto revisar un momento específico en la historia del arte reciente del arte chileno - la participación no-oficial de Chile en la XII Bienal de Paris- incorporando a su lectura las características que hemos descrito para el arte contemporáneo. Desde este estudio, hemos propuesto que la escritura sobre arte se vuelve en este período artístico una herramienta cada vez más importante: acompaña a las obras en su apropiación y resignificación de los lenguajes heredados de las tradiciones e historias del arte. En este sentido, situar por medio de la palabra escrita las obras que se dan a conocer en una determinada exhibición, forma parte del ejercicio expositivo, diagramando horizontes perceptivos que promuevan una determinada lectura de las obras, en ocasiones desmarcándolas

explícitamente de una secuencia evolutiva en el desarrollo de una historia del arte, como en el caso que analizamos.

Ahora bien, estas inscripciones, si bien necesarias, no son siempre recibidas como se espera. Las expectativas del envío chileno, por ejemplo, se vieron frustradas. Aun así, la voluntad de organizar y hacer circular a la Escena de Avanzada como tal, es decir, como un conjunto articulado de prácticas artísticas, no se cerró en esta experiencia, sino que culminó cuatro años más tarde con la publicación de Margins and Institutions. Art in Chile since 1973, texto que 
Outros Tempos, vol. 19, n. 33, 2022, p. 90-116. ISSN: 1808-8031

concentra la narración de ese conjunto, promoviendo su unidad desde la lectura. Los textos, como las exhibiciones, dependen de su receptor y las entradas de lectura que este dé a lo que ve o lee. Si pensamos que nos encontramos todavía en el contexto del síntoma del arte contemporáneo, lo que significa que aún no se ve el panorama completo, sino sólo señales que lo anuncian, podemos leer este desplazamiento - o la sensación que transmiten los participantes - de la escena local hacia las historias del arte occidentales a una inmadurez de las "vanguardias simultáneas", que acontecen legítimamente en sus lugares de origen pero se ven enfrentadas a la dificultad de ser reconocidas como tal en los centros, que aún tienen las pautas para la legitimización de las prácticas artísticas. Los reclamos de las periferias por ser recibidos desde sus particularidades vendrán en la década de los noventa, con publicaciones como Beyond the Fanstastic: Contemporary art criticism from Latin America (MOSQUERA, 1995). El giro hacia el arte contemporáneo permite que poco a poco la atención se vaya desplazando hacia los márgenes y crezca el interés por conocer y dar su lugar a las prácticas artísticas surgidas más allá de las historias del arte europeo o norteamericano.

Este giro nos lleva a otra problemática, la de las identidades latinoamericanas que, enfrentadas al escenario internacional con sede en el occidente del llamado primer mundo (sea en las principales ciudades de Europa, como en este caso, o en EE. UU.), buscan ser miradas como legítimamente iguales y diferentes. Iguales en su capacidad de producir manifestaciones artísticas originales, y diferentes en su condición de "culturas híbridas", citando la expresión de García Canclini, en las que conviven lo moderno occidental con las culturas de "origen". Ser considerados legítimamente iguales y diferentes significa poder participar, desde esa diferencia, en igualdad de condiciones en los eventos internacionales: que la mirada extranjera no domine, desde sus claves preconcebidas, las novedades que se le presentan, sino que sepa ver esa novedad. En este sentido, construir teóricamente una escena permite manifestar su originalidad, sobre todo - como hemos insistido sostener -, al interior de un sistema de circulación de las formas artísticas, en la que los lenguajes han quedado disponibles a su uso. Puede que esta idea transforme, en cierto sentido, al mundo artístico contemporáneo en una comunidad de lectores especializados, donde la inscripción de las obras en catálogos y su reseña en libros y revistas especializadas, es tan importante como su exhibición frente al público. Pero esta es una fórmula que nos permite exponer y compartir distintos horizontes de sentido, desde las claves que hacen 
Outros Tempos, vol. 19, n. 33, 2022, p. 90-116. ISSN: 1808-8031

sentido a quien se enfrenta a las obras. Así, podemos expandir la apertura que inicia el arte conceptual hacia la mirada del espectador.

\section{Imágenes}

Figura 1 - Portada del catálogo de la XII Bienal de París, 1982.

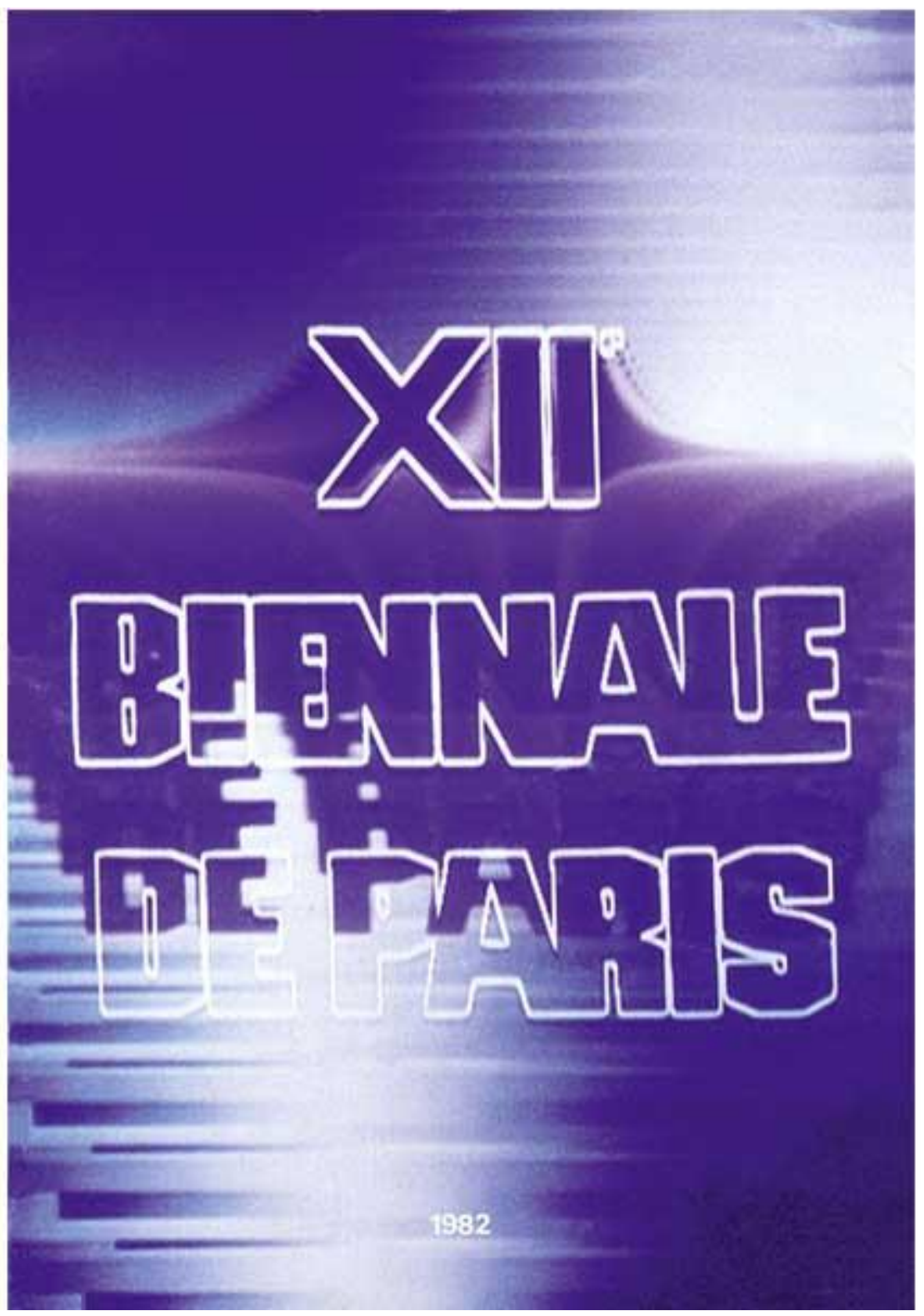

Fonte: Archivo Pedro Montes 
Outros Tempos, vol. 19, n. 33, 2022, p. 90-116. ISSN: 1808-8031

Figura 2 - Portada de la revista Art Press, Septiembre de1982.

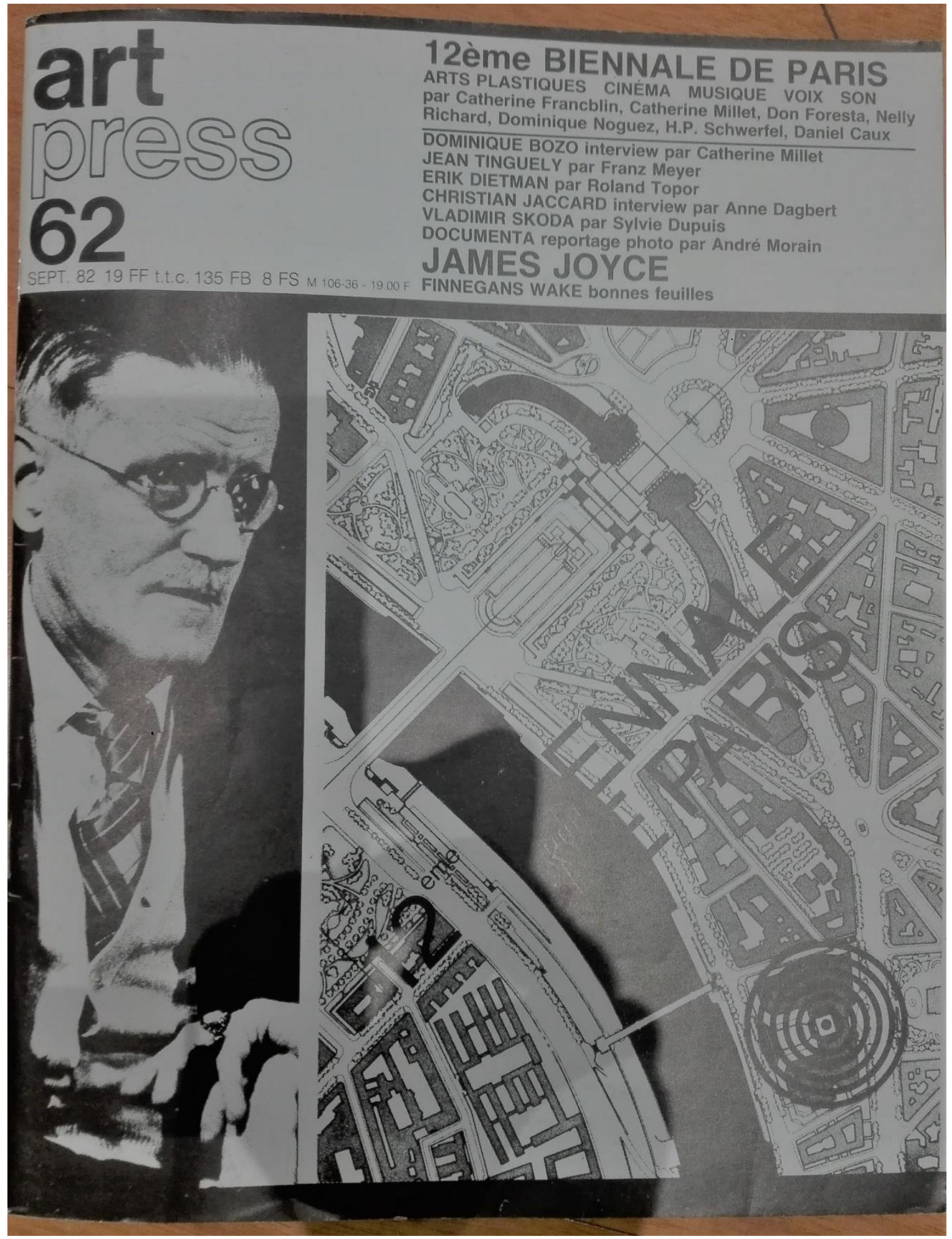

Fonte: Archivo Pedro Montes 
Outros Tempos, vol. 19, n. 33, 2022, p. 90-116. ISSN: 1808-8031

Figura 3 - Portada del catálogo "Cabeza partida" del artista Samy Benmayor. Galería Plástica 3, 1986.

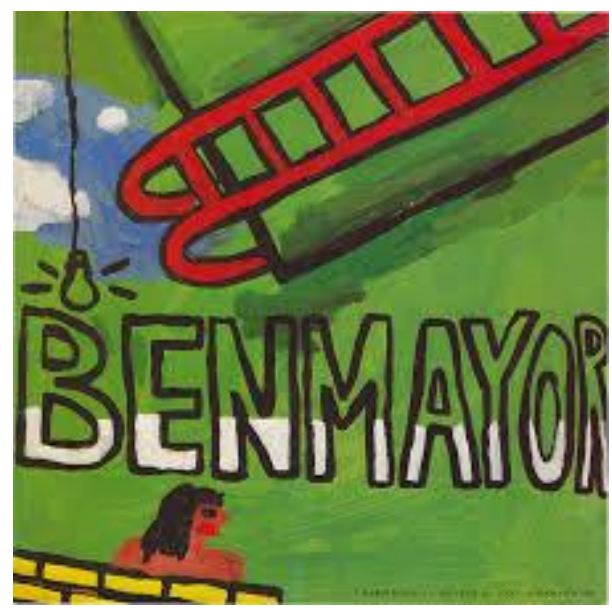

Fonte: CENTRO DE DOCUMENTACIÓN DE LAS ARTES VISUALES. Cabeza partida. Galería Plástica 3, Santiago de Chile, ago. 1986. Disponible en:

http://centrodedocumentaciondelasartes.cl/g2/collect/cedoc/images/pdfs/4041.pdf. Acceso en: 19 mayo 2021.

\section{Referencias}

\section{Documentos}

\section{a) Medios electrónicos}

CATÁLOGO de la I Bienal de París. Disponible en: http://archives.biennaledeparis.org/fr/1959/ Acceso en: 15 jun. 2017.

CENTRO DE DOCUMENTACIÓN DE LAS ARTES VISUALES. Cabeza partida. Galería Plástica 3, Santiago de Chile, ago. 1986. Disponible en:

http://centrodedocumentaciondelasartes.cl/g2/collect/cedoc/images/pdfs/4041.pdf. Acceso en: 19 mayo 2021.

DEBEUSSCHER, Juliane. From cultural diplomacy to artistic and curatorial experimentation: the Paris Youth Biennale between 1965 and 1973. Institut of the Present, 2020. Disponible en: https://institutulprezentului.ro/en/2020/09/10/from-cultural-diplomacy-to-artistic-and-curatorialexperimentation-the-paris-youth-biennale-between-1965-and-1973/. Acceso en: 19 mayo 2021.

OSBORNE, Peter. Every other year is this year: contemporaneity and the Biennial Form. Making Biennials in Contemporary Times. Essays from the World biennial Forum n. 2, São Paulo, 2014. Biennial Foundation, 2014. Disponible en:

https://www.biennialfoundation.org/2015/05/available-now-online-making-biennials-incontemporary-times-essays-from-the-world-biennial-forum-no-2/. Acceso en: 15 mayo 2021. 
Outros Tempos, vol. 19, n. 33, 2022, p. 90-116. ISSN: 1808-8031

RICHARD, Nelly. Nelly Richard sobre su curaduría para la Bienal de Venecia. [Entrevista cedida a] Lucy Quezada. Revista Artishock, 11 dic. 2014. Disponible en:

http://artishockrevista.com/2014/12/11/nelly-richard-curaduria-la-bienal-venecia/. Acceso en: 10 jun. 2018.

\section{b) Revistas y publicaciones periódicas}

Art Press, n. 62, sept. 1982.

Cal, n. 2, jul. 1979.

La Separata, n. 2 mayo 1982.

La Separata, n. 6 out.1983.

Pluma y Pincel, n. 2, 11 enero 1983.

\section{Bibliografía}

BERRÍOS, María; MACHUCA, Guillermo. Arte y contextos: tres décadas de producción artística en Chile. In: MOSQUERA, Gerardo (ed.). Copiar el Edén: arte reciente en Chile. Santiago: Puro Chile ediciones, 2010.p. 65-87.

BIENNALE DE PARIS. XII Biennale de Paris: exhibition catalogue. Paris, sept., 1982.

DANTO, Arthur C. Después del fin del arte. El arte contemporáneo y el linde de la historia, Barcelona: Paidós, 2003.

GALAZ, G.; IVELIC, M. Chile arte actual. Valparaíso: Ediciones Universitarias de Valparaíso, 1988.

GALENDE, Federico. Filtraciones I: conversaciones sobre arte en Chile (de los 60`s a los 80`s). Santiago: Arcis; Cuarto Propio, 2007.

GIUNTA, Andrea. ¿Cuándo empieza el arte contemporáneo?: when does contemporary art begin? Buenos Aires: Fundación arteBA, 2014.

MACHIAVELLO, Carla. Vanguardia de exportación: la originalidad de la Escena de Avanzada y otros mitos chilenos. In: MACHIAVELLO, C.; CARVAJAL, F.; DELPIANO, M. J. Ensayos sobre artes visuales: prácticas y discursos de los años '70 y '80 en Chile. Santiago: Lom ediciones, 2011. p. 85-112.

MACHUCA, Guillermo. El traje del emperador: arte y recepción pública en el Chile de las cuatro últimas décadas. Santiago: Ediciones Metales Pesados, 2009. 
Outros Tempos, vol. 19, n. 33, 2022, p. 90-116. ISSN: 1808-8031

MELLADO, Justo Pastor; RICHARD, Nelly. Cuadernos de/para el análisis. Santiago: Autoedición, 1983.

MOSQUERA, Gerardo (ed.). Beyond the Fantastic. Contemporary Art Criticism From Latin America. London: iniVA, 1995.

NEUSTADT, Roberto. Cada día: la creación de un arte social. Santiago: Editorial Cuarto Propio, 2001.

O`NEILL, Paul. "The curatorial turn. From practice to discourse” In: RUGG, Judtih; SEDGWICK, Michèle (ed.). Issues in curating contemrporary art. Bristol: Intellect Boos, 2007. p 13-28.

OSBORNE, Peter. The postconceptual condition or, the cultural logic of high capitalism today. Radical Philosophy, n. 184, p. 19-27, 2014.

RICHARD, Nelly. La escena de avanzada y su contexto histórico-social. In: MOSQUERA, Gerardo (ed.). Copiar el Edén: arte reciente en Chile. Santiago: Editorial Puro Chile, 2006. p. 103-111.

RICHARD, Nelly. Márgenes e instituciones: arte en Chile desde 1973. Santiago: Metales Pesados, 2009.

RICHARD, Nelly. Archivos de arte chileno, memoria y resistencia crítica, 2007. In: PARRA, Diego (ed.). Reescrituras y contraescrituras de la Escena de Avanzada. Santiago: Departamento de Artes Visuales, Facultad de Artes de la Univeridad de Chile, 2020. p. 131-175.

VARAS, Paulina. Cartografía crítica del conceptualismo en América Latina (1960-1980). 2015. (Tesis de Doctorado Història de l'Art) - Universidad de Barcelona, Barcelona, 2015.

VARAS, Paulina. De la vanguardia artística chilena a la circulación de la Escena de Avanzada. ICAA MFA, Houston, n. 1, p. 54-61, sept. 2017.

WILLIAMSON, Luz María. Memoria y amnesia: sobre la historia del arte reciente en Chile, 1976-2006. 2014. Tesis para optar al grado de doctor. Facultad de Bellas Artes, Universidad Complutense de Madrid, Madrid, 2014. 